\title{
Derin Anterior Lameller Keratoplasti Sonuçlarımız
}

\section{Outcomes of Our Patients Who Underwent Deep Anterior Lamellar Keratoplasty}

\author{
Aslı ÇETINKKAYA YAPRAK, Mustafa ÜNAL
}

Akdeniz Üniversitesi Tıp Fakültesi Göz Hastalıkları AD, Antalya, Türkiye

Yazışma Adresi

Correspondence Address

\section{Aslı ÇETINKAYA \\ YAPRAK}

Akdeniz Üniversitesi Tıp Fakültesi

Göz Hastalıkları AD, Antalya,

Türkiye

aslickaya@yahoo.com

Geliş tarihi / Received : Ara 30, 2020 Kabul tarihi / Accepted : Oca 19, 2021 Elektronik yayın tarihi : Eyl 01, 2021 Online published

\section{Bu makalede yapılacak atıf: \\ Cite this article as: \\ Çetinkaya Yaprak A \\ Ünal M. \\ Derin Anterior Lameller \\ Keratoplasti Sonuçlarımız}

Akd Tıp D / 2021; 7(3):366-371

Aslı ÇETINKAYA YAPRAK ORCID ID: 0000-0002-4285-419X Mustafa ÜNAL

ORCID ID: 0000-0001-8358-6390

\section{ÖZ}

Amaç:

Sağlıklı endotele sahip gözlerde büyük hava kabarcığı tekniği ile uyguladığımız derin anterior lamellar keratoplasti (DALK) perioperatif komplikasyonları ve klinik sonuçlarını sunmayı amaçladık.

\section{Yöntem:}

Derin anterior lamellar keratoplasti uyguladığımız 105 hastanın 120 gözünün verileri retrospektif olarak incelendi. Preoperatif muayeneleri, operasyon verileri, intraoperatif ve postoperatif komplikasyonlar, ek girişimler ve görsel sonuçlar değerlendirildi.

\section{Bulgular:}

Çalışmaya $54(\% 51,5)$ kadın, $51(\% 48,5)$ erkek hasta dahil edildi. Ortalama yaş 30,9 $\pm 13,8$ (12-75) idi. Preoperatif endikasyonlar keratokonus $80(\% 66,7)$, korneal distrofi $20(\% 16,7)$ göz, travmatik yüzeyel nefelyon $8(\% 6,7)$, postherpetik keratit $6(\% 5)$, kimyasal yanık $2(\% 1,6)$, Salzmann nodüler dejenerasyonu $1(\% 0,8)$ ve nonspesifik korneal opasite $3(\% 2,5)$ gözde mevcuttu. 96 (\%80) gözde büyük hava kabarcığı tekniği ile Descement membranı ayrıştırıldı. 4 $(\% 3,3)$ gözde aşamalı manuel diseksiyon yapıldı. Postoperatif düzeltilmiş en iyi görme keskinliği $5 / 10$ ve üzerinde toplam 29 göz mevcuttu. Hastaların ölçülebilen gözlerde sferik ve keratometrik astigmatizma değerleri sırasıyla $-2,50 \pm 2,25$ ve $-2,50 \pm 2,25$ idi. İki hastada stromal greft reddi izlendi ve medikal tedaviyle düzeldi. Dört hastada postoperatif glokom gelişti ve bir hastaya trabekülektomi uygulandı.

\section{Sonuç:}

Sağlıklı endotele sahip olgularda büyük hava kabarcığı tekniği ile DALK cerrahisi etkili bir yöntemdir. Görsel ve refraktif sonuçları standart yöntem olan penetran keratoplasti ile benzerdir, endotelyal greft reddi riskini ortadan kaldırması çok büyük bir avantaj sağlamaktadır.

Anahtar Kelimeler: Büyük hava kabarcığı tekniği, Derin anterior lameller keratoplasti, Greft ömrü

\section{Summary: \\ Objective:}

We aimed to present the perioperative complications and clinical outcomes of deep anterior lamellar keratoplasty (DALK) performed with the big-bubble technique in eyes with healthy endothelium. 


\section{Methods:}

The data of 120 eyes of 105 patients who underwent deep anterior lamellar keratoplasty were analyzed retrospectively. Preoperative examinations, operation data, intraoperative and postoperative complications, additional interventions and visual results were evaluated.

\section{Results:}

Fifty-four (51.5\%) female and 51 (48.5\%) male patients were included in the study. The mean age was $30.9 \pm 13.8$ (12-75). Regarding the preoperative indications, $80(66.7 \%)$ eyes had keratoconus, 20 (16.7\%) corneal dystrophy, 8 (6.7\%) traumatic superficial nephelion, $6(5 \%)$ postherpetic keratitis, 2 ( $1.6 \%)$ had chemical burn, $1(0.8 \%)$ had Salzmann nodular degeneration, and $3(2.5 \%)$ had nonspecific corneal opacity. Descement membrane was separated in $96(80 \%)$ eyes using the big-bubble technique. Layer-by-layer manual dissection was performed in 4 (3.3\%) eyes. There were a total of 29 eyes with postoperative best corrected visual acuity of $5 / 10$ or better. Spherical and keratometric astigmatism values in the measurable eyes of the patients were $-2.50 \pm 2.25$ and $-2.50 \pm$ 2.25 , respectively. Stromal graft rejection was observed in 2 patients and it resolved with medical treatment. Postoperative glaucoma developed in 4 patients and trabeculectomy was performed in 1 patient.

\section{Conclusion:}

DALK surgery with big-bubble technique is an effective method in patients with healthy endothelium. Its visual and refractive outcomes are similar to the standard method of penetrating keratoplasty, and its elimination of the risk of endothelial graft rejection provides a tremendous advantage.

Key Words: Big-bubble technique, Deep anterior lamellar keratoplasty, Graft survey

\section{Giriş}

Derin anterior lameller keratoplasti (DALK) keratokonus, korneal skar, stromal distrofi ve stromal dejenerasyon gibi endoteli etkilemeyen bir çok korneal stromal patolojide uygulanan bir tedavi yöntemidir (1). DALK'ın penetran keratoplastiye (PK) kıyasla avantajları sağlıklı kornea endotelinin ve glob bütünlüğünün korunması, endotel hücre kaybının az olması ve endotel immünolojik reaksiyon riskinin olmamasıdır. DALK sonrası topikal kortikosteroid kullanım süresi daha azdır ve bu da ilaca bağlı gelişecek olan sekonder infeksiyon, katarakt ve glokom riskini azaltmaktadır $(2,3)$.

Anwar ve Teichmann büyük hava kabarcığı tekniğini tanımlayana kadar ara yüz düzensizliği ve alıcı korneada rezidü skar dokusu problemleri nedeniyle DALK yaygınlaşmadı. Büyük hava kabarcığı DALK tekniğinin bu sınırlamaların üstesinden geldiği ve PK ile kıyaslandığında daha yüksek görme keskinliği sağladığı görüldü $(4,5)$.

Bu retrospektif çalışmada kliniğimizde DALK cerrahisi uyguladığımız hastalarımızın preoperatif ve postoperatif sonuçlarını sunmayı amaçladık.

\section{Gereç ve Yöntem}

$\mathrm{Bu}$ çalışma, Akdeniz Üniversitesi Klinik Araştırmalar Etik Kurulu'ndan onay alındıktan sonra Helsinki Bildirgesi ilkelerine bağlı kalınarak yürütüldü ve uzmanlık tezinden üretildi. Çalışma geriye dönük olarak tasarlandı ve Haziran 2007 Aralık 2013 tarihleri arasında aynı cerrah (MÜ) tarafından farklı tanılarla DALK ameliyatı uygulanmak üzere ameliyata alınmış verilerine ulaşılabilen 105 hastanın 120 gözü çalışma kapsamına alındı. DALK uygulanabilenlere ait postoperatif sonuçlar ayrıca değerlendirildi.

Ameliyat öncesi tüm alıcı hastalar kliniğimiz kornea biriminde değerlendirildi. Hastaların ayrıntılı anamnezleri alındı; yaş, cinsiyet, sistemik hastalık, geçirilmiş oküler cerrahi sorguland1; görme keskinlikleri, otorefraktometre değerleri (KR-8900; Topcon), en iyi düzeltilmiş görme keskinlikleri, göz içi basınç değerleri (CT-800 Bilgisayarlı Tonometre; Topcon), ön ve arka segment muayeneleri yapıldı; patolojik bulgular kaydedildi. DALK için kontrendikasyon oluşturacak patolojilerin de varlığı araştırıldı. Retinal vasküler hastalık gibi ek bir oküler patolojisi bulunanlar, hidrops geçirmiş olanlar ve Descemet membranında (DM) skar bulunan hastalar çalışma dışı bırakıldı.

\section{Cerrahi Prosedür}

Hastaların 110'u (\%91,7) genel anestezi, 10’u (\%8,3) lokal anestezi altında ameliyat edildi. Genç ve çocuk hastalarda genel anestezi tercih edilirken, ileri yaşta ve sistemik problemi olan hastalarda lokal anestezi tercih edildi. Lokal anestezi yöntemi olarak periferik akinezi ile retrobulber veya subtenon anestezi uygulandi.

Tüm hastalara Anwar ve Teichmann tarafindan tanımlanan büyük hava kabarcığı DALK uygulandı. Alıcı yatak vakum trepan (Hessburg-Barron Vacuum Trephine, U.S.) kullanılarak kornea kalınlığının yaklaşık \%70'ini içerecek şekilde trepanize edildi.

Hava dolu 1 ml'lik bir enjektöre 30 gauge (G) iğne takıld1, iğne ucu yaklaşık $45^{\circ}$ açıyla $\sim 5 \mathrm{~mm}$ eğildi. Kesi yerinden korneal stromanın merkezine doğru iğnenin eğimli ucu aşağ1da olacak şekilde yaklaşık 3-4 mm ilerletildi. İntrastromal hava enjeksiyonu yapıldı ve büyük hava kabarcığı oluşturulmaya çalışıldı. İlk denemede hava kabarcığ 1 oluşmayan olgularda, başka bir giriş yerinden tekrar ikinci ve üçüncü denemeler yapıldı. Havanın kornea stroması altına yayıldığı ve korneanın beyaz bir disk hâlini aldığı durumda büyük hava kabarcı̆̆ı oluştuğu kabul edildi.

Yirmi G bıçak yardımıyla parasentez yapılarak ön kamara basınc1 düşürüldü. Kresent ve $45^{\circ}$ bıçaklar yardımıyla ön korneal stroma uzaklaştırıldı. Kalan stroma dokusu dikkatli bir şekilde $45^{\circ}$ bıçak yardımıyla delinerek büyük kabarcık boşaltıldı. DM ve stroma ara yüzeyine viskoelastik madde verildi. Kalan stroma dokusu makas ucu bu delikten girilerek kesildi ve çıkarıldı. Böylece altta sadece DM kalmış oldu. Büyük kabarcık oluşmayanlarda ise aşamalı manuel lameller diseksiyon tekniğine geçildi. Kresent bıçak veya künt uçlu iris spatulu stroma katları arasında ilerletilerek tünel oluşturuldu. Sonrasında tünel genişletilerek korneal katlar uzaklaştırıldı. Tüm stromal katlar bu şekilde kaldırılarak DM'na ulaşılmaya 
çalışıld1.

Alıcı yatak ve donör kornea çapları cerrah tarafindan belirlendi. Donör kornealar mekanik el trepanı (Barron Marking Donor Punch, U.S.) ile kesildi. Dokunun endotel tarafi görünebilirliğini artırmak için tripan mavisi ile boyandı. İnce bir penset veya kuru üçgen sünger kullanılarak donörün endoteli ve DM soyuldu. Çalışmanın son yıllarına doğru donör DM'nin yırtılmadan yekpare soyulabildiği durumlarda bu doku DMEK cerrahisinde kullanılmak üzere ayrıldı. Bu işlem sırasında ara yüzeyde yabancı cisim kalmaması için ara yüzey, serum fizyolojik ile dikkatlice temizlendi. Donör doku alıcı yatağa 10/0 naylon monoflaman sütür ile sütüre edildi. Sütürasyon tekniği olarak 16 devamlı ve sekiz tek sütür kombinasyonu veya 16 tek sütür teknikleri kullanıldı. Çocuk hastalarda subkonjonktival deksametazon (Dekort $2 \mathrm{ml} 8 \mathrm{mg}$ ampül) enjeksiyonu yapıld 1 ve cerrahi sonlandırıldı. Penetran keratoplastiye geçilen olgularda ayrıca intrakamaral olarak $1 \mathrm{mg} / 0,1 \mathrm{ml}$ moksifloksasin HCL (Vigamox \%0,5 $5 \mathrm{ml}$ oftalmik solüsyon, Alcon) uyguland.

Hastalar postoperatif birinci gün, birinci hafta, bir, üç, altıncı aylarda ve sonrasinda altı ay arayla muayene edildi. Her kontrolde rutin oküler muayene yapıldı. Tek sütürlerde gevşemeye bağlı olarak batma ve rahatsızlık hissi oluştuğunda sütür alındı. Astigmat ayarı için sütür alımlarında tek seferde genellikle tek veya iki sütür alındı. Sorunsuz takip edilen olgularda öncelikli olarak astigmat ayarlanması için kornea topografisi kılavuzluğunda tek sütürler alınmaya devam edildi.

\section{İstatistik}

İstatistiksel analizler SPSS for Windows 18.0 (Statistical Product and Service Solutions, Inc.,Chicago, IL, ABD) paket programı ile gerçekleştirildi. Verilerin değerlendirilmesinde tanımlayıcı istatistiksel metodları (ortalama, standart sapma) kullanıldı. Sonuçlar \%95'lik güven aralığında değerlendirildi. P değeri 0.05 alındi.

\section{Bulgular}

Derin anterior lameller keratoplasti işlemi yapmak üzere ameliyatına başlanan 105 hastanın 120 gözü çalışmaya dahil edildi. On dokuz gözde DM makroperforasyonu, bir gözde de DM uzanan skar nedeniyle toplam 20 gözde PK geçildi. Preoperatif ve intraoperatif veriler 120 göz, postoperatif veriler ise 100 göz üzerinden değerlendirildi.

Yaşları 12-75 arasında (ort.30,9 $\pm 13,8$ ) olan 54 kadın ve 51 erkek çalışmaya dahil edildi. Hastaların 80 'inde keratokonus, 20 'sinde korneal distrofi, 8'inde travmatik yüzeyel nefelyon, 6'sında herpetik keratit sekeli, 2'sinde kimyasal yanık, 1 'inde Salzman nodüler dejenerasyonu ve 3 'ünde nonspesifik korneal opasite mevcuttu (Tablo I).
Tablo I Preoperatif Hasta Bilgileri

\begin{tabular}{|l|l|}
\hline Demografik Özellikler & Hasta Sayısı (n=105) \\
\hline Yaş (yıl) $^{\text {a }}$ & $30,9 \pm 13,8(12-75)$ \\
\hline Cinsiyet (Kadın/Erkek) & $54 / 51(\% 51,4 / \% 48,6)$ \\
\hline Sağ/sol göz & $35 / 55(\% 33,3 / \% 52,4)$ \\
\hline Bilateral göz & $15(\% 14,3)$ \\
\hline Takip Süresi (ay) ${ }^{\text {a }}$ & $36,1 \pm 11,2(6-60)$ \\
\hline Preoperatif Tanılar & Göz Sayısı (n=120) \\
\hline Keratokonus & $80(\% 66,7)$ \\
\hline Korneal Distrofi & $20(\% 16,7)$ \\
\hline Travmatik Yüzeyel Nefelyon & $8(\% 6,7)$ \\
\hline Herpetik Keratit Sekeli & $6(\% 5)$ \\
\hline Kimyasal Yanık & $2(\% 1,6)$ \\
\hline Salzman Nodüler Dejenerasyon & $1(\% 0,8)$ \\
\hline Nonspesifik Korneal Opasite & $3(\% 2,5)$ \\
\hline
\end{tabular}

a: Ortalama ve standart sapma (aral1k)

Tablo II İntraoperatif Bulgular

\begin{tabular}{|l|l|}
\hline & Göz Sayısı $\left(\mathbf{n}=\mathbf{1 0 0}^{*}\right)$ \\
\hline Sütür Tekniği & \\
\hline 8 tek ve 16 devamlı & $20(\% 20)$ \\
\hline 16 tek & $80(\% 80)$ \\
\hline Trepan Çapı & \\
\hline $7.25-7.50$ & $3(\% 3)$ \\
\hline $7.50-7.75$ & $68(\% 68)$ \\
\hline $7.75-8.00$ & $27(\% 27)$ \\
\hline $8.00-8.25$ & $2(\% 2)$ \\
\hline
\end{tabular}

*: DALK cerrahisi sorunsuz tamamlanan hastaların verileri değerlendirildi.

Derin anterior lameller keratoplasti uygulanan 100 gözün intraoperatif verileri (trepan çapları, sütür teknikleri) Tablo II de özetlenmiştir. 
İntraoperatif ve postoperatif komplikasyonlar Tablo III'te gösterilmiştir.

Tablo III İntraoperatif Bulgular

\begin{tabular}{|l|l|}
\hline İntraoperatif Komplikasyonlar & Sayısı (n=120) \\
\hline Hava Kabarcı̆̆ı Oluşturamama & $24(\% 20)$ \\
\hline $\begin{array}{r}\text { Penetran Keratoplastiye Geçiş } \quad \text { DM Makroperforasyon } \\
\text { DM Opasitesi }\end{array}$ & $\begin{array}{l}20(\% 16,7) \\
19(\% 15,8) \\
1(\% 0,8)\end{array}$ \\
\hline DM Mikroperforasyon & $10(\% 8,3)$ \\
\hline DM Rezidü Stroma & $4(\% 3,3)$ \\
\hline Postoperatif Komplikasyon & Sayısı (n=100) \\
\hline Korneal Arayüz Düzensizliği & $8(\% 8)$ \\
\hline DM Kırışıklı̆̆ı & $5(\% 5)$ \\
\hline Sütür Kopması & $4(\% 4)$ \\
\hline Çift Ön Kamara & $4(\% 4)$ \\
\hline Korneal Arayüz Opasitesi & $3(\% 3)$ \\
\hline Steroid Kullanımına Bağlı Glokom & $3(\% 3)$ \\
\hline Stromal Rejeksiyon & $2(\% 2)$ \\
\hline Korneal Epitelyal Düzensizlik & $1(\% 1)$ \\
\hline Akut Açı Kapanma Glokomu & $1(\% 1)$ \\
\hline Katarakt Gelişimi & $1(\% 1)$ \\
\hline
\end{tabular}

DM: Descement Membran1, G: Gauge

Keratoplasti uyguladığımız 120 gözün 29'unda DM perforasyonu izlendi. Bunlardan 19'u makroperforasyon, 10'u mikroperforasyondu. Mikroperforasyon gelişen 10 gözde de ise cerrahi DALK olarak tamamland. Makroperforasyonlar üç gözde hava kabarcığ 1 oluşturma esnasında, 14 gözde yeterli bir hava kabarcığının oluşmaması nedeniyle manuel olarak aşamalı diseksiyon sırasında ve iki gözde $30 \mathrm{G}$ enjektörün ön kamaraya girmesine bağlı olarak meydana geldi. Bir gözde ise stroma başarılı olarak uzaklaştırıldıktan sonra korneal patolojinin santral bölgede DM'nı da etkilediği görüldüğünden PK'ye geçildi. Dolayısıyla 120 gözün 20'sinde (\%17) intraoperatif komplikasyonlar nedeniyle DALK cerrahisi uygulanmayıp PK yapıld1.

Ameliyat esnasında toplam 96 gözde hava kabarcığı sorunsuz şekilde oluşturulabildi (\%80). Bu gözlerin 36 tanesinde Anwar ve Teichmann'ın tarif ettiği şekilde ilk enjeksiyonda hava kabarcığı oluşturulabildi. Atmış gözde ise ikinci veya üçüncü kez hava enjeksiyonu uygulaması gerekti. Hava kabarcığı bir ya da daha fazla denemede oluşturulamayan 24 DALK işleminde (\%20) aşamalı manuel lameller diseksiyon ile stroma uzaklaştırıldı. Keratokonus ve korneal distrofi olan gözlerde hava kabarcığı oluşturma başarı oranı daha yüksek iken (\%86) korneal skar olan gözlerde hava kabarcığı oluştur- ma oranı $(\% 50)$ daha düşük bulundu.

Postoperatif komplikasyonlar sorunsuz DALK cerrahisi uygulanan 100 göz üzerinden değerlendirildi. Postoperatif çift ön kamara 4 gözde (\%4) oluştu. Gözlerin birinde kendi kendine rezorbe olduğu izlendi, diğer gözlere postoperatif ikinci hafta ön kamaraya C3F8 gazı enjeksiyonu uygulandı. Dört gözde de sorunsuz olarak iyileşme izlendi. Sekiz gözde (\%8) korneal arayüz düzensizliği görüldü. Beş gözde (\%5) DM kırışıklığı, üç gözde (\%3) korneal ara yüzde yabancı cisim varlığ hava olmayan bir gözde (\%1) postoperatif akut açı kapanması glokomu oluştu. Hastanın intraoküler basıncı (IOB) medikal tedaviyle kontrol altına alındı. Dört gözde (\%4) postoperatif sütüre bağlı komplikasyon gelişti. Spontan sütür açılması nedeniyle üç göze sütür revizyonu yapıldı. Revizyon sonrasinda, hasta takiplerinde herhangi bir ek komplikasyon gelişmedi. Bir gözde ise DALK cerrahi sonrası üçüncü ayda geçirdiği travmaya bağlı olarak sütür revizyonu yapıldı. Bu gözde uzun dönem takipleri sonrası kistoid makula ödemi geliştiği ve buna bağlı olarak görme düşüklüğü olduğu görüldü. İki gözde (\%2) stromal rejeksiyon atağı gelişti. Saat başı topikal kortikosteroid damla ve pomad tedavisi ile sorunsuz iyileşti.

Görsel ve refraktif sonuçlar sorunsuz DALK cerrahisi uygulanan 100 göz üzerinden değerlendirildi (Tablo IV).

Tablo IV Görsel ve Refraktif Sonuçlar

\begin{tabular}{|l|l|l|}
\hline Görme Keskinliği & Preoperatif & Postoperatif \\
\hline DGK 1/10 alt1 & $44(\% 44)$ & $10(\% 10)$ \\
\hline DGK 1/10 ve üstü & $56(\% 56)$ & $90(\% 90)$ \\
\hline DGK 5/10 ve üstü & $0(\% 0)$ & $29(\% 29)$ \\
\hline DEGK 1/10 altı & $37(\% 37)$ & $0(\% 0)$ \\
\hline DEGK 1/10 ve üstü & $63(\% 63)$ & $100(\% 100)$ \\
\hline DEGK 5/10 ve üstü & $1(\% 1)$ & $74(\% 74)$ \\
\hline Refraksiyon & & $-2,50 \pm 2,25$ \\
\hline Sferik Değer ${ }^{\text {a }}$ & $-9,75 \pm 3,75$ & $-2,50 \pm 2,25$ \\
\hline Keratometrik & $-7,75 \pm 3,25$ & \\
\hline Astigmatizma & & \\
\hline
\end{tabular}

DGK: Düzeltilmemiş görme keskinliği,

DEGK: Düzeltilmiş en iyi görme keskinliği

a: Ortalama ve standart sapma

Hastalar keratoplasi ameliyatı sonrası ortalama 36,1 ay (6-60 ay) takip edildi. Preoperatif düzeltilmemiş görme keskinliği (DGK) 1/10-5/10 olan 56 göz (\%56) mevcuttu, 5/10 ve üzerinde olan göz yoktu; düzeltilmiş en iyi görme keskinliği (DEGK) ise 1/10 ve üzeri olan 63 göz (\%63), 5/10 ve üzeri olan 1 göz (\%1) mevcuttu. Postoperatif DGK $1 / 10$ ve üzerinde olan 90 göz (\%90), 5/10 ve üzerinde olan 29 göz (\%29) mevcuttu; DEGK ise 1/10 ve üzeri olan 100 göz (\%100), 5/10 ve üzeri olan 74 göz (\%74) mevcuttu. Korneal ara yüz düzen- 
sizliği olan sekiz gözde postoperatif DEGK 3/10 ve 10/10 arasında değişmekte idi ve diğer gözlerle kıyaslandığında istatistiksel olarak anlamlı bir fark bulunmadı $(p=0.418)$. Refraktif sonuçlar Tablo IV'te özetlendi. Hastaların preoperatif sferik değerleri ölçülebilen gözlerde $-15,50$ ile $+1,50$ aras1 (ort. $-9,75 \pm 3,75$ ), keratometrik astigmatizma değerleri ise $-9,50$ ile $+2,50$ arası (ort. $-7,75 \pm 3,25$ ) olarak ölçüldü. Postoperatif sferik değerler $-7,50$ ile $+4,25$ arası (ort. $-2,50 \pm 2,25$ ), keratometrik astigmatizma değerleri ise $-7,50$ ile $+4,25$ aras1 (ort. $-2,50 \pm 2,25$ ) ölçüldü. Yüksek astigmatizma bulunan hastalarda postoperatif erken dönemde selektif sütür alımı uyguland1.

\section{Tartışma}

Penetran keratoplasti günümüzde halen en s1k uygulanan korneal transplant yöntemidir (6). Cerrahi aletlerde, cerrahi teknikte ve korneal greft teknolojisindeki gelişmeler greft ömrünün uzamasını sağlamıştır. $\mathrm{Bu}$ avantajlara rağmen immün aracılı endotelyal greft reddi greft başarısızlığının önde gelen en önemli nedeni olmaya devam etmektedir. DALK cerrahisinde alıcı korneal endotel korunup, immün aracılı endotelyal greft reddini ortadan kaldırdığ 1 için sağlıklı endotele (distrofiler, travma ve postenfeksiyöz keratit ile ilişkili keratokonus ve stromal opasiteler) sahip gözlerde PK'ye alternatif olarak popülerlik kazanmıştır.

Biz hastalarımızda Anwar ve Teichmann tarafindan bildirilen büyük hava kabarcığg tekniğini uyguladık. Hava kabarcığ1 oluşturmada başarı oranımızı \%80 olarak bulduk. Bu oranın literatürde daha önce bildiren oranlarla (\%40-\%100) benzer olduğunu görülmektedir (7-9). İlk uygulamada başarılı olmayan hastalarda ikinci ve üçüncü defa hava enjeksiyonu uyguladık. Hava kabarcı̆̆ı oluşturma başarı oranlarını keratokonusta $\% 86$, korneal skarda ise $\% 50$ olarak bulundu. Korneal skar olan hastalarda hava kabarcığı oluşturma oranı keratokonus hastalarından çok daha düşük oldu. Bunun nedeni korneal skar dokusunun, hava kabarcığı oluşumunu ve DM ayrışmasını zorlaştırması olabilir.

Hava kabarcı̆̆ı oluşturma esnasında ya da cerrahinin takip eden diğer aşamalarında 29 hastada $(\% 24,1)$ DM perforasyonu gelişti. Literatürdeki DM perforasyon oranları keratokonus hastalarında $\% 8-\% 20$ ve korneal skar olan hastalarda \%14-\%39,2 olarak bildirilmiştir (4,10-16).

Descemet membranı makroperforasyonu gelişen 19 hasta ve DM'na uzanan skar bulunan bir hastada (toplamda \%16,7) PK'ye geçildi. Bu oranın, sadece keratokonus hastalarında uygulanan DALK cerrahilerinde daha düşük olduğu gösterilmiştir. Yapılan benzer çalışmalarda DM makroperforasyonuna bağlı PK' ye geçiş oranı \%4-\%39,2 aralığında bildirilmiştir (13-15,17). Bizim çalışmamızda da nispeten yüksek oranda bir DM makroperforasyonuna bağlı PK'ye geçiş izlendi. Bu seride bulunan bu yüksek oranın nedeni hem korneal skar olan hastaların hem de bu tekniğin kliniğimizde ilk uygulanmaya başlandığı olguların çalışmaya dahil edilmesi olabilir. Öte yandan hava kabarcığı oluşturma esnasında ya da cerrahinin herhangi bir aşamasında DM mikroperforasyonu gelişen \%8,3 hastada DALK cerrahisi sorunsuz şekilde tamamland 1 .
Alıcı yatak DM ve donör arasında oluşan çift ön kamara nispeten yaygın görülen bir postoperatif komplikasyondur. Çift ön kamara dört (\%4) hastada meydana geldi. Yapılan çalışmalarda çift ön kamara oluşma oranı \%0-\%16 arasında olduğu bildirilmiştir (18). Çift ön kamara bir hastada kendiliğinden rezorbe oldu, diğer üç hastada ise ön kamaraya C3F8 enjeksiyonu uygulaması sonrasında tamamen geriledi. İkinci enjeksiyon gereksinimi oluşmadı.

Derin anterior lameller keratoplasti cerrahisinde tek, devamlı ve kombine tarzda sütür teknikleri uygulanabilmektedir. Postoperatif refraktif değerlerde sütür tekniklerinin birbirine üstünlüğü gösterilmemiştir (19). Biz de sütürasyon tekniği olarak genellikle 16 tek sütürü kullandık, az sayıda hastada 16 devamlı ve sekiz tek sütür kombinasyonu da kullanıldı. Sorunsuz takip edilen olgularda astigmat ayarlanması için postoperatif üçüncü aydan itibaren kornea topografisi kılavuzluğunda tek sütürler alındı, devamlı sütürler ise bir yılın sonunda alındi.

Postoperatif düzeltilmiş en iyi görme keskinliklerine bakıldığ1 zaman, 5/10 ve üzeri görme keskinliğine sahip hasta oranını \%74 olarak bulduk. Diğer çalışmalarla kıyaslandığı zaman bu oran biraz düşük olduğu görülmektedir $(7,10,11,15,16)$. Göreceli olarak kısa takip süresi, korneal patolojilerin çeşitliliği ve öğrenme dönemine ait DALK sonuçlarının da çalışmada yer alması bu düşüklüğe neden olmuş olabilir. Literatürde lameller keratoplasti sonrası görsel sonuçların zamanla düzelme eğiliminde olduğu bildirilmiştir $(7,15,16,20)$.

Postoperatif sferik değer ve keratometrik astigmatizma verileri önceki çalışmalardaki verilerle karşılaştırıldığ 1 zaman sonuçlar benzer bulundu $(21,22)$. PK serileriyle karşılaştırdığımız zaman da sonuçların yine benzer olduğunu gördük $(2,11,23)$.

Başarılı büyük hava kabarcığı oluşturma, başarılı bir DALK cerrahisi anlamına gelmemektedir. Bizim çalışmamızda tüm mikroperforasyonlar ve iki makroperforasyon, başarılı büyük hava kabarcığı oluşturulduktan sonra kalan periferal rezidü stromanın eksizyonu aşamasında meydana geldi. Kalan periferik rezidü stromanın eksizyonu çok dikkatli bir şekilde yapılmalıdır. Hava enjeksiyonu sonrası yapılacak korneal parasentez, intraoküler basıncı düşürerek bu komplikasyonun oluşma riskini azaltabilir.

\section{Sonuç}

Descement membranı ve endotel bütünlüğü sağlam olan hastalarda uygulanabilen DALK cerrahisi, immünolojik reaksiyonu ve greft reddi riskini büyük oranda azaltmaktadır. Yara iyileşmesinin daha hızlı olması, intraoküler komplikasyonların daha az olması, postoperatif enfeksiyon riskinin daha az olması, endotel sayısı yetersiz veya daha uzun süre beklemiş donörlerin kullanılabilmesi, postoperatif dönemde lokal steroid tedavi süresinin kısalması nedeniyle steroid kullanımına bağlı komplikasyonların riskinin azalması gibi önemli avantajları mevcuttur. Ayrıca DM sağlam kaldığında yara yeri travmaya daha dirençlidir ve PK hastalarından daha erken dönemde sütürler alınabilir. PK üzerine olan bütün bu avantajları göz önüne alındığında uygun hastalarda öncelikle DALK cerrahisi denenmelidir. 
Etik Komite Onayı: $\mathrm{Bu}$ araştırma, ilgili tüm ulusal düzenlemelere, kurumsal politikalara ve Helsinki Bildirgesinin ilkelerine uygundur ve Akdeniz Üniversitesi Tıp Fakültesi Etik Kurulu tarafından onaylanmıștır (onay numarası: 2013/319)

Yazar Katkıları: Fikir - M.Ü.; Tasarım - M.Ü.; Denetleme/Danışmanlık - M.Ü.; Veri Toplanması ve/veya İşlemesi A.Ç.Y.; Analiz ve/veya Yorum - A.Ç.Y.; Literatür Taraması A.Ç.Y.; Makalenin Yazımı - A.Ç.Y.; Eleştirel İnceleme M.Ü.; Kaynaklar ve Fon Sağlama - A.Ç.Y.; Malzemeler A.Ç.Y.

Hasta Onamı: Geriye yönelik bir çalışma olduğu için alınmamıştır.

Çıkar Çatışması: Yazarların beyan edecek çıkar çatışması yoktur.

Finansal Destek: Yazarlar bu çalışma için finansal destek almadıklarını beyan etmişlerdir.

Bu makale Prof. Dr. Mustafa Ünal'ın danışmanlığında

Dr. Aslı Çetinkaya Yaprak’ın Akdeniz Üniversitesi Hastanesi Göz Hastalıkları Anabilim Dalı'nda yapmış olduğu uzmanlık tezinden üretilmiştir.

\section{Kaynaklar}

1. Reinhart WJ, Musch DC, Jacobs DS, Lee WB, Kaufman $\mathrm{SC}$, Shtein RM. Deep anterior lamellar keratoplasty as an alternative to penetrating keratoplasty a report by the american academy of ophthalmology. Ophthalmology. 2011;118: 209-218.

2. Bahar Kaiserman I, Srinivasan S, Ya-Ping J, Slomovic AR, Rootman DS. Comparison of three different techniques of corneal transplantation for keratoconus. Am J Ophthalmol. 2008;146:905-912.

3. Ardjomand N, Hau S, McAlister JC, Bunce C, Galaretta D, Tuft SJ, Larkin DF. Quality of vision and graft thick ness in deep anterior lamellar and penetrating corneal allografts. Am J Ophthalmol. 2007;143:228-235.

4. Anwar M, Teichmann KD. Big-bubble technique to bare Descemet's membrane in anterior lamellar keratoplasty. J Cataract Refract Surg. 2002;28:398-403.

5. Shimazaki J, Shimmura S, Ishioka M, Tsubota K. Randomized clinical trial of deep lamellar keratoplasty vs penetrating keratoplasty. Am J Ophthalmol. 2002; 134:159-165.

6. Tan DT, Mehta JS. Future directions in lamellar corneal transplantation. Cornea 2007;26 (9 suppl 1):21-28.

7. Fontana L, Parente G, Tassinari G. Clinical outcome after deep ante $\neg$ rior lamellar keratoplasty using the big-bubble technique in patients with keratoconus. Am J Ophthal mol. 2007; 143:117-124.

8. Fogla R, Padmanabhan P. Results of deep lamellar keratoplasty using the big-bubble technique in patients with keratoconus. Am J Ophthal $\neg$ mol. 2006;141:254-259.

9. Borderie VM, Werthel A, Touzeau O, Allouch C, Bout boul A, Laroche L. Comparison of techniques used for removing the recipient stroma.

10. Al-Torbak AA, Al-Motowa S, Al-Assiri A, Al-Kharashi
S, Al-Shahwan S, Al-Mezaine H, Teichmann K. Deep anterior lamellar keratoplasty for keratoconus. Cornea. 2006;25:408-412.

11. Noble BA, Agrawal A, Collins C, Saldana M, Brogden PR, Zuber $\neg$ buhler B. Deep anterior lamellar keratoplasty (DALK): visual out $\neg$ come and complications for a heterogeneous group of corneal pathol $\neg$ ogies. Cornea. 2007;26:59-64.

12. Michieletto P, Balestrazzi A, Balestrazzi A, Mazzotta C, Occhipinti I, Rossi T. Factors predicting unsuccessful big bubble deep lamellar anterior keratoplasty. Ophthalmo logica. 2006;220:379-382.

13. Watson SL, Ramsay A, Dart JK, Bunce C, Craig E. Com parison of deep lamellar keratoplasty and penetrating keratoplasty in patients with keratoconus. Ophthalmolo gy. 2004;111:1676-1682.

14. Sugita J, Kondo J. Deep lamellar keratoplasty with complete removal of pathological stroma for vision improvement. Br J Ophthalmol. 1997;81:184-188.

15. Coombes AG, Kirwan JF, Rostron CK. Deep lamellar keratoplasty with lyophilised tissue in the management of keratoconus. Br J Oph $\neg$ thalmol. 2001;85:788-791.

16. Amayem AF, Anwar M. Fluid lamellar keratoplasty in keratoconus. Ophthalmology. 2000;107:76-80.

17. Feizi S, Javadi MA, Jamali H, Mirbabaee F. Deep Anteri or Lameller Keratoplasty in Patients with Keraoconus: Big-Buble Technique. Cornea. 2010;29:177-82.

18. Kubaloglu A, Sari ES, Unal M, Koytak A, Kurnaz E, Cinar Y, Ozertürk Y. Long-term results of deep anterior lamellar keratoplasty for the treatment of keratoconus. Am J Ophthalmol. 2011;151:760-767. e761.

19. Javadi MA, Naderi M, Zare M, Jenaban A, Rabei HM, Anissian A. Comparison of the effect of three suturing techniques on postkeratoplasty astigmatism in keratoco nus. Cornea 2006;25:1029-33.

20. Benson WH, Goosey CB, Prager TC, Goosey JD. Visual improve $\neg$ ment as a function of time after lamellar kerato plasty for keratoconus. Am J Ophthalmol. 1993;116:207-211.

21. Söğütlü Sari E, Kubaloğlu A, Ünal M, Piñero Llorens D, Koytak A, Ofluoglu AN, Özertürk Y. Penetrating kerato plasty versus deep anterior lamellar keratoplasty: Com parison of optical and visual quality outcomes. $\mathrm{Br} \mathrm{J}$ Ophthalmol 2012;96:1063-7.

22. Yeung SN, Lichtinger A, Kim P, Amiran MD, Rootman DS. Retrospective contralateral study comparing deep anterior lamellar keratoplasty with penetrating kerato plasty: A patient's perspective. Can J Ophthalmol 2012;47:360-4.

23. Funnell CL, Ball J, Noble BA. Comparative cohort study of the out $\neg$ comes of deep lamellar keratoplasty and penetrating keratoplasty for keratoconus. Eye. 2006;20:527-532. 